\title{
Self-Management Support Intervention for Parents of Children with Developmental Disorders: The Role of Gratitude and Hope
}

\author{
Faith Martin $\mathbb{1}^{1} \cdot$ Wendy Clyne ${ }^{2} \cdot$ Gemma Pearce $^{2} \cdot$ Andy Turner $^{2}$
}

Published online: 13 February 2019

(c) The Author(s) 2019

\begin{abstract}
Objectives Many parents of children with developmental disabilities, including autism spectrum disorders and attention deficit disorders, experience poor well-being and increased anxiety and depression. Very few interventions directly target parents' needs. The peer-delivered HOPE Programme was designed to address this with six weekly group sessions focusing on self-management skills, including goal setting and expressing gratitude.

Methods This pre-post study aimed to examine changes in anxiety, depression, well-being, hope and gratitude, and to explore associations between changes in anxiety and depression and changes in gratitude and hope. Validated measures of depression, anxiety, positive well-being, gratitude and hope were used. Parents of children with a range of developmental disabilities, most commonly autism spectrum disorders, were recruited.

Results Of 137 (86.9\% female) recruited, 108 parents completed the course and post-course data. Parents' depression, anxiety, well-being, gratitude and hope all significantly improved between baseline and post-course. Hope and gratitude correlated significantly with depression, anxiety and well-being. Baseline depression, baseline gratitude, post-course hope and gratitude explained $50 \%$ of the variance in post-course depression. Reduced work hours, and baseline and post-course hope and gratitude explained $40 \%$ of the variance in post-course well-being. Anxiety was not associated to hope nor gratitude at either time point.

Conclusions This study provides initial support for feasibility and potential effect of the peer delivered self-management intervention on parental anxiety and depression. Changes in gratitude and hope account for some change in depression, but not anxiety. A randomised controlled trial is needed to establish efficacy and explore mechanisms of change in-depth.
\end{abstract}

Keywords Autism spectrum disorders $\cdot$ Parents $\cdot$ Self-management $\cdot$ Well-being $\cdot$ Developmental disability

Research has documented elevated levels of parental stress and distress experienced by parents raising children with developmental disorders (DD) or disabilities, such as autism spectrum disorder (ASD), attention deficit hyperactivity disorder (ADHD), or other learning disabilities (Gordon and Hinshaw 2015; Hassall and Rose 2005; Hayes and Watson 2013; Johnston and Mash 2001). There are some specific differences between stressors reported by parents of children with different DD. For example, ADHD has been linked to greater attachment difficulties than ASD (Miranda

Andy Turner

a.turner@coventry.ac.uk

Department of Psychology, University of Bath, Bath, UK

2 Centre for Advances in Behavioural Science, Coventry University, Coventry, UK et al. 2015). However, there are several shared features among the stressors described by parents of children with various DD (Gupta 2007). These parents are typically managing more challenging behavior than parents of children without these conditions (Hall and Graff 2012). They may also be faced with social challenges, such as lower social support (perceived or objectively measured; Heiman and Berger 2008), and stigmatizing attitudes from others owing to their child's behavior (Kinnear et al. 2016). Whilst many parents cope well with these demands, some experience clinically significant levels of anxiety and/or depression (Falk et al. 2014; Weiss 2002). Given the reciprocal relationship between parental and child distress (Herring et al. 2006), it is important to address parental distress for the parents and wider family.

As with all parents, parents of children with ASD and other DD employ a variety of coping strategies, including seeking social support from those in similar situations, 
using formal support from health and social care services, and engaging in reframing and positive reappraisals (Twoy et al. 2007). To manage stress, some parents seek out peer support groups, for greater emotional support and social resources (Clifford and Minnes 2013). Peer delivered selfmanagement interventions, focusing on improving an "individual's ability to manage the symptoms, treatment, physical and psychosocial consequences and life style changes inherent in living with a chronic condition" (Barlow et al. 2002, p. 178), are effective in a range of conditions including improving mental health (Cyhlarova et al. 2015). These approaches may be of use, but have not yet been tried with parents with children with DD.

There are few interventions that address parental mental health and well-being for those with children with DD such as ASD (Da Paz and Wallander 2017; Dababnah and Parish 2016). Interventions often focus on improving parenting strategies (Dababnah and Parish 2015) or directly attempting to address child outcomes (Bibby et al. 2002). Whilst these approaches may achieve a positive impact on the family, they do not address parental well-being directly (Dababnah and Parish 2015). It is often assumed that changes in child behaviour will lead to shifts in parental well-being (Karst and Van Hecke 2012).

There is a gap in interventions adressing parental mental health and well-being, and few interventions that address social support for these parents (Krakovich et al. 2016). A recent literature review identified only thirteen interventions for mental health of parents/carers of children with ASD, with insufficient evidence to comment on their efficacy for addressing a range of parental well-being outcomes (Da Paz and Wallander 2017). Mindfulness based interventions, emotional writing, and acceptance commitment therapy interventions demonstrated medium effect sizes on parental well-being, including measures of stress and depression. Some of these interventions were self-adminstered, which may not address the sense of isolation and lack of peer support that many parents with children with DD experience (Ekas et al. 2016). Of note was an RCT that used peer mentors and tested a positive psychology based intervention using experiental exercises that included gratitude and optimism over 6 weeks of group sessions (Dykens et al. 2014). Post-intervention distress, depression and anxiety scores were all significantly reduced compared to baseline. It is not clear if this intervention is effective at reducing distress where depression or anxiety are at clinically significant levels. Many of these intervention require highly skilled and trained staff or require intensive training for peer-tutors. For example, the positive psychology based intervention entailed a four month training programme (Dykens et al. 2014). This increases costs and therefore potential barriers to implementation at scale. Scaleable interventions to support parental well-being are required.
Peer-delivered, self-management interventions based on positive psychology may be of use, given parents' use of peer-support groups and initial evidence for the utility of positive psychology techniques (Dykens et al. 2014). Many interventions addressing well-being and mental health focus on deficit models (Grant et al. 2010). A fruitful avenue for intervention research may be fostering positive psychological emotional states, which researchers have emphasised the importance of to improving outcomes (Brooks et al. 2015; Veres et al. 2014).

Hope and gratitude may be highly relevant positive psychological states, important to the well-being of parents of children with DD. Preliminary research shows gratitude to be a useful self-management technique for supporting parents of children with ASD (Joshi et al. 2013). Research with people affected by long-term conditions of various types has found the focus on hope and gratitude to be highly relevant and demonstrate early evidence of improving wellbeing (Turner and Martin 2017).

Hope is defined as "a positive motivational state that is based on an interactively derived sense of successful (a) agency (goal-directed energy) and (b) pathways (planning to meet goals)" (Snyder et al. 1991, p. 287). Hope then includes cognitive aspects of motivation and perceived routes to complete goals, which must be seen as having a valuable outcome (Snyder et al. 2002). Hope is a cognitive process, which in contrast to related concepts such as selfefficacy, can be general, cross-situational goal-directed thinking, as well as focusing on specific behaviors or desired outcomes (Snyder 1995).

Hope has both direct and indirect effects on depression symptoms: hope affects coping appraisals and behaviors and has a direct impact as a cognitive process in its own right (Arnau et al. 2007; Chang and DeSimone 2001; Geiger 2013; Kwon 2000). Hope is also related to anxiety symptoms (Arnau et al. 2007) and is independently related to well-being (Magaletta and Oliver 1999). There are few studies reporting a causal relationship between hope and mental health (Schrank et al. 2008). There are some randomized control trials of hope theory-based interventions (Cheavens et al. 2006) which show reduced symptoms of depression and anxiety. In relation to parents of children with DD, hope is indirectly associated with depression symptoms, via family support and loneliness, in mothers of children with ASD (Ekas et al. 2016). Increasing hope may then improve depression.

Gratitude is defined as a positive cognitive-affective experience involving the recognition of an event that has created positive emotion (Emmons and McCullough 2003). Gratitude cannot be self-directed but can be directed at a specific person, event or a more general set of circumstances (Wood et al. 2010). It is both a mood state and a trait that is practiced, with the latter being most researched 
in its relation to experience of well-being (Emmons and McCullough 2003). Gratitude is related to improved interpersonal relationships (Lambert et al. 2010), reduced negative mood (Fredrickson et al. 2000), greater resilience, well-being and coping (Tugade et al. 2004), and significantly predicts lower depression and anxiety symptoms (Petrocchi and Couyoumdjian 2016). Cultivating gratitude can improve depression scores (Bolier et al. 2013), although not all studies report reduction in depression or anxiety scores where distress is at clinical levels of severity (Kerr et al. 2015). Little research has explored the relationship between gratitude and parental well-being for those with children with DD, however, initial research has suggested gratitude interventions may be beneficial for parental wellbeing (Timmons et al. 2017; Timmons 2015).

The extent to which change in hope and gratitude may be causal in improving depression or anxiety scores in these parents is unknown. Identifying mechanisms of change is complex and requires satisfaction of multiple criteria, including the first step of establishing strong association between the intervention, mechanism and outcome, and then exploring other elements including consistency of this change; and change in the mechanism preceding change in the outcome (Kazdin 2007).

Our primary aim was to complete an initial exploration of the impact of a positive psychology based selfmanagement intervention, the "HOPE Programme", for parents of children with DD, including ASD. We aim to examine the intervention's impact on hope and gratitude, and on parental anxiety symptoms, depression symptoms, and positive mental well-being. The intervention has core components designed to directly address gratitude and hope. The design of the study allowed initial investigation of the potential utility of the intervention, and provided basic insight into feasibility of conducting the intervention, in terms of examining retention rates, participant's evaluation of the course content, organisation and management, and evidencing that it was indeed possible to run the intervention. Our second aim was to explore whether gratitude and hope scores are associated to depression and anxiety scores at post-intervention, taking baseline scores into account.

\section{Method}

\section{Participants}

Participants were parents (or family members assuming a parental role) of a child with a DD. This mixed group of parents of children with DD is owing to the similarities in stressors across DDs, and the aims and nature of the intervention being to improve parental well-being, rather than e.g., provision of specific instructions on how to intervene with behaviours related to specific diagnoses of ASD, ADHD etc. Parents attended the HOPE Programme, delivered at Coventry Carers Trust, Heart of England Centre. Parents can self-refer, following receipt of a leaflet from the Carers' Centre or word-of-mouth information, or can be referred by support services at schools, social services and the children's neurodevelopmental service in Coventry. All parents who sought to attend the programme were potential participants. No exclusions were made on the basis of the child's diagnosis, as all parents had children with some form of developmental difficulty, either parent reported only or parent report of clinician confirmed diagnosis. Only one parent from each family attended. The study used a convenience sample. Details of participants' characteristics are in Table 1.

The parent's report of child's diagnoses was collected. Of the 137 participants providing data at baseline, 4 had diagnosis not confirmed by clinician (parent reported only). Some had diagnoses other than ASD $(n=26)$, of which 13 had only one diagnosed condition (11 ADHD, one OCD and one global developmental delay) and 13 had multiple diagnoses. Of the 112 with an ASD diagnosis, 58 had only an ASD diagnoses and 54 had comorbidities, most commonly ADHD $(n=21)$. Other comorbidities included nonspecified learning disability $(n=10)$, epilepsy (7), sensory processing disorder (6), dyspraxia (4), sleep disorder (4), dyslexia (3), Tourette's' (2), depression (2), neurofibromatosis (2), and attachment disorder, OCD, conduct disorder, cerebral palsy and Kline Felter syndrome (each reported only once).

\section{Procedure}

At baseline (start of intervention) and post-course (end of intervention), participants completed the measures of anxiety, depression, well-being, hope and gratitude. At baseline, participants also completed the demographic questionnaire previously described.

The development of the HOPE Programme was guided by the Medical Research Council framework for developing complex interventions (Craig et al. 2008). This involved consultations with DD professionals and parents of childrens with DD. The HOPE Programme is a group, face-toface intervention of six weekly sessions lasting around $2.5 \mathrm{~h}$. Table 2 outlines the intervention content. The intervention manual may be requested from the authors. Our book chapter provides further details on HOPE intervention development and an example of its implementation (Turner and Martin 2017).

The intervention seeks to directly increase hope and gratitude. Techniques to increase hope include hearing of others' successful activities, talking with people about goals, and goal setting with reward upon achievement 
Table 1 Characteristics and Baseline Scores between those who did/not Complete Postcourse Measures

\begin{tabular}{|c|c|c|c|}
\hline & $\begin{array}{l}\text { Total sample at } \\
\text { baseline }(n=137)\end{array}$ & $\begin{array}{l}\text { Completed post-course } \\
\text { data }(n=108)\end{array}$ & $\begin{array}{l}\text { Non-completers } \\
(n=29)\end{array}$ \\
\hline Variable & Mean (s.d.) & Mean (s.d.) & \\
\hline Age parent & $39.7(7.55)$ & $39.4(7.43)$ & $40.8(8.03)$ \\
\hline Age child & $\begin{array}{l}9.7(4.57) \text { (range } \\
3-28)^{\dagger \dagger}\end{array}$ & 9.8 (4.76) (range 3-28) & $\begin{array}{l}9.6(3.79) \text { (range } \\
4-16)\end{array}$ \\
\hline Time since diagnosis (months) & $10.6(20.46)$ & $12.1(22.48)^{*}$ & $5.0(8.33)^{*}$ \\
\hline Baseline depression score & $9.1(4.31)$ & $9.0(4.36)$ & $9.8(4.15)$ \\
\hline Baseline anxiety score & $11.7(4.31)$ & $11.7(4.67)$ & $11.8(2.65)$ \\
\hline Baseline well-being score & $38.9(8.83)$ & $38.8(8.48)$ & $39.3(10.16)$ \\
\hline Baseline hope score & $25.5(9.20)$ & $25.9(9.42)$ & $24.0(8.31)$ \\
\hline \multirow[t]{2}{*}{ Baseline gratitude score } & $28.4(7.15)$ & $28.6(7.01)$ & $27.4(7.73)$ \\
\hline & Frequency $(\%)$ & Frequency $(\%)$ & Frequency $(\%)$ \\
\hline Parent attending is mother & $117(85.4)$ & $92(85.2)$ & $25(86.2)$ \\
\hline Parent attending is father & $10(7.3)$ & $8(7.4)$ & $2(6.9)$ \\
\hline $\begin{array}{l}\text { "Parent" attending is another } \\
\text { family member in parental role }\end{array}$ & $10(7.3)$ & $8(7.4)$ & $2(6.9)$ \\
\hline Parent gender - female & $119(86.9)$ & $93(86.1)$ & $26(89.7)$ \\
\hline Gender child - female & $37(27.0)$ & $27(25.0)$ & $10(34.5)$ \\
\hline Parent has medical problems & $72(52.6)$ & $53(49.1)$ & $19(65.5)$ \\
\hline $\begin{array}{l}\text { Completed formal education (to } \\
\text { age 16) }\end{array}$ & $100(73.0)$ & $79(73.1)$ & $21(72.4)$ \\
\hline In paid employment & $49(35.8)$ & $40(37.0)$ & $9(31.0)$ \\
\hline $\begin{array}{l}\text { Has cut back on work hours } \\
\text { owing to child's needs }\end{array}$ & $35(25.5)$ & $26(24.1)$ & $9(31.0)$ \\
\hline Has siblings & $119(86.9)$ & $92(85.2)$ & $27(93.1)$ \\
\hline \multicolumn{4}{|l|}{ Ethnicity } \\
\hline White European & $117(85.4)$ & $91(84.3)$ & $26(89.7)$ \\
\hline Other & $20(14.6)$ & 17 (15.7) & $3(10.3)$ \\
\hline \multicolumn{4}{|l|}{ Marital status } \\
\hline Single & $25(18.2)$ & $21(19.4)$ & $4(13.8)$ \\
\hline Married & $58(42.3)$ & $47(43.5)$ & $11(37.9)$ \\
\hline Other & $54(39.4)$ & $40(37.0)$ & $14(48.3)$ \\
\hline Has ASD diagnosis confirmed & $112(81.8)$ & $83(76.9)^{* *}$ & $29(100)^{* *}$ \\
\hline
\end{tabular}

†The group "Completed post course measures" refers to those who attended at least 3 sessions and completed end of course questionnaires, non-completers refers to those who attended fewer than 3 sessions

${ }^{\dagger}$ Four parents had children over the age of 17 , as we asked for age of the oldest child with DD. These parents also had children aged 17 or under with DD

*Significantly different at $p<0.05$

**Significant association between group and variable at $p<0.005$
(Snyder 1995). As such, every session includes goal setting and feedback from the week. Presenting participants with examples of how participants have benefitted from the course in session one is designed to instill hope. Learning techniques that can be useful to managing stress and wellbeing may also provide hope for the future, as does focusing on strengths (Larsen et al. 2015). Gratitude is explicitly addressed each session with the gratitude diary, shown to be as effective as more complex CBT techniques, such as thought monitoring and cognitive restructuring, often with lower attrition rates (Wood et al. 2010). Other intervention content aims to offer practical strategies for managing stress and improving well-being, such as managing anger and using breathing techniques.

The HOPE Programme was delivered by pairs of trained parents of children with DD. Facilitator training is "minimal" in that it encompasses a 2 day classroom-based training course. The classroom training involves training in motivational interviewing (e.g., reflective listening) and behaviour change skills (e.g., goal setting, action planning), group facilitation skills (e.g., managing challenging behaviours) and delivery practice of intervention activities. A 
Table 2 HOPE Programme Content

\begin{tabular}{|c|c|}
\hline Session number & Session activities \\
\hline Session 1 & $\begin{array}{l}\text { Welcome, introduction and ground rules } \\
\text { What is self-management? } \\
\text { Instilling hope: The upward spiral of positivity } \\
\text { Diaphragmatic breathing } \\
\text { Gratitude diary } \\
\text { Goal setting and action planning }\end{array}$ \\
\hline Session 2 & $\begin{array}{l}\text { Welcome and reflections from last week's session } \\
\text { Solution focused goal feedback } \\
\text { Gratitude diary } \\
\text { Managing stress } \\
\text { Introduction to mindfulness } \\
\text { Goal setting and action planning }\end{array}$ \\
\hline Session 3 & $\begin{array}{l}\text { Welcome and reflections from last week's session } \\
\text { Solution focused goal feedback } \\
\text { Gratitude diary } \\
\text { Dealing with child's anger issues } \\
\text { Managing fatigue } \\
\text { Guided imagery } \\
\text { Goal setting and action planning }\end{array}$ \\
\hline Session 4 & $\begin{array}{l}\text { Welcome and reflections from last week's session } \\
\text { Solution focused goal feedback } \\
\text { Gratitude diary } \\
\text { Anger management in children } \\
\text { Communication } \\
\text { Goal setting and action planning }\end{array}$ \\
\hline Session 5 & $\begin{array}{l}\text { Welcome and reflections from last week's session } \\
\text { Solution focused goal feedback } \\
\text { Gratitude diary } \\
\text { Behavior issues and setting limits } \\
\text { Get active and feel good } \\
\text { Goal setting and action planning }\end{array}$ \\
\hline Session 6 & $\begin{array}{l}\text { Welcome and reflections from last week's session } \\
\text { Solution focused goal feedback } \\
\text { Gratitude diary } \\
\text { Character strengths } \\
\text { Life priorities } \\
\text { Motivational imagery } \\
\text { Sharing successes } \\
\text { Moving on and staying in touch }\end{array}$ \\
\hline
\end{tabular}

facilitator's manual helps to ensure consistency of delivery and content. Facilitators were trained and checked against a rigorous set of quality standards relating to the core components of the course, examining intervention delivery, focusing on adherence to the timing, sequence and coverage of activities as set out in the manual. To pass training, facilitators are observed delivering a session and assessed using a fidelity checklist, on which they had to pass every item to be rated as "passed". Ongoing support was provided by one of the authors (AT), who is an experienced selfmanagement trainer, having trained over 500 peer and professional facilitators. This approach to training is designed to create quality and fidelity, whilst minimsing costs to increase ease of potential large-scale implementation.

A convenience sample of participants attending the first 13 courses was used sequentially over a 2 -year period. No changes were made to the intervention during this period. The study was approved by Coventry University Ethics Committee.

\section{Measures}

At baseline, participants completed a demographic questionnaire regarding their age, gender, presence of medical problems, completion of formal education (up to 16 years), whether in paid employment, if they had cut back on working hours owing to child's needs, ethnicity, and marital status; and the age of their child, child's gender, time since diagnosis (months), if there are siblings, and if ASD diagnosis has been confirmed. Established, validated measures were used for depression, anxiety, well-being, hope and gratitude.

Depression and anxiety were measured using the Hospital Anxiety and Depression Scale (HADS) (Zigmond and Snaith 1983). The HADS has two 7-item subscales (anxiety and depression). Each item is rated 0-3. Scores for each item are added to form two separate sub-scale scores, ranging from 0 to 21, with higher scores indicating greater levels of anxious or depressed mood. Example items are "I feel tense or "wound up" (anxiety) and "I feel as if I am slowed down" (depression). This measure also provides an indication of probable "clinical caseness", as scores of 11 or above indicate probably clinically significant levels of depression or anxiety (Crawford et al. 2001). A change from a score of 11 or above at baseline to below 11 at postcourse suggests a "recovery" from that clinical level of depression or anxiety to a sub-clinical or normal level. We use the clinical terms "caseness" and "recovery" to describe participants' scores on these measures, without claiming that our intervention is the cause of such changes or that these methods offer diagnostic robustness. This is no substitute for a full clinical assessment and diagnosis, but these scores suggest that clinical levels of distress are likely. The HADS has been found to have good reliability and validity for the detection of anxiety and depression (for a review see Bjelland et al. 2002). The measure has been used with parents of children with DD, including autism, with good internal reliability evidenced by Cronbach alpha 0.85 for anxiety and 0.80 for depression (Padden and James 2017), which was also found supported in our study (alpha 0.83 for anxiety and 0.86 for depression). 
Positive mental well-being was measured using the Warwick-Edinburgh Mental Well-being Scale (WEMWBS) which assesses emotional and cognitive dimensions of wellbeing, and positive psychological functioning. The WEMWBS is a 14 item scale, scored $1-5$, providing a total positive mental well-being score between 14-70. Higher scores represent greater positive mental well-being. Items include "I've been feeling good about myself" (Tennant et al. 2007). Internal reliability (Cronbach's alpha 0.91 in Tennant et al. 2007 and 0.92 in the current study) and testretest reliability (correlation 0.83 ) are good, and there is evidence for validity based on expected correlations with related constructs including affect, and quality of life (Tennant et al. 2007).

The Gratitude Questionnaire (GQ-6) is a self-report scale measuring disposition to experience gratitude (McCullough et al. 2002). Participants answer 6 items on a 1 to 7 scale (1 = "strongly disagree", $7=$ "strongly agree"), for example, "I have so much in life to be thankful of". Scores range from 6-42. Higher scores representing higher levels of gratitude. The measure has good internal reliability (Cronbach alphas between 0.82 and 0.87 in McCullough et al. 2002 and 0.85 in the current study) and validity, evidenced through high correlations with optimism, life satisfaction, hope, depression and anxiety (McCullough et al. 2002).

Hope was measured using the Adult State Hope Scale, which was designed to measure goal-directed thinking and focus as a momentary state (Snyder et al. 1996). It comprises 6-items scored 1-8, for example, "There are lots of ways around any problem that I am facing now". Items are summed to provide the total score, ranging from 6 to 48 . Higher scores represent more hope. The measure has good reliability (Cronbach alphas 0.79 to 0.95 reported in Snyder et al. 1996, and 0.91 in the current study) and validity as evidenced by strong correlations with related constructs of self-esteem and affect (Lopez et al. 2000).

The Health Education Impact Questionnaire or "HEIQ" (Osborne et al. 2007) is a short questionnaire that rapidly assesses the perceived impact of self-management interventions of participants by asking about their views and experience of the course. Participants rated their agreement with the statements from 1-4, with 4 being the highest and most positive score. Example items include "Difficult topics and discussions were handled well by the programme leaders" and "I thought that programme content was very relevant to my situation".

\section{Data Analysis}

Demographic variables and baseline scores were compared for those who attended at least three of the six intervention sessions and completed post-course measures versus those who dropped out. Any observed differences were then explored in further detail. Three or more sessions is commonly used as a cut-off point for completion of six session self-management interventions (Griffiths et al. 2005).

Participants were included in further analysis comparing baseline and post-course outcome scores if they attended at least three of the six HOPE programme sessions. Baseline and post-course scores were compared using paired sample t-tests. Effect sizes (Cohen's d) were calculated and standard boundaries were used were used to determine small (0.2), moderate (0.5) and large effect sizes (0.8) (Cohen 1988).

Descriptive statistics for change between baseline and post-course for outcomes measures (depression, anxiety, well-being) and psychological variables (hope and gratitude) were calculated for those who did recover from clinical caseness versus those who did not. This was completed using the HADS cut-off scores for depression and anxiety separately. Basic correlations were calculated between depression, anxiety, gratitude and hope at both time points.

Stepwise multiple linear regression was used to examine the amount of variance in the outcomes of change between baseline and post-course for anxiety and depression (calculated separately) that is explained by (1) parent characteristics (age, gender, in paid employment, cut down work hours); (2) child characteristics (age, gender, only child/has siblings); and (3) baseline and post-course gratitude and hope. These variables were added to the model in these three blocks, using the stepwise method. Only variables significantly explaining variance in the outcome were retained in the final model. Collinearity was assessed, examining condition indices using the cut off of 15 to indicate possible collinearity and 30 to indicate a severe problem with collinearity (Hair et al. 2010). Time since diagnosis was not included as this had been shown to have no correlation with baseline anxiety, depression, well-being, hope or gratitude (see results described below). All data were analysed using IBM SPSS Version 23.

\section{Results}

\section{Characteristics of Participants and Comparisons of those who Completed Post-Course vs. did not}

A total of 137 participants (parents or carers of child/ren with DD) attended the first 13 courses. At least three of six sessions, and therefore also post-course data, were completed by 108 of these participants. Details of the characteristics and demographic variables are reported in Table 2. The retention rate was $78.8 \%$ (course completed and post-course data collected from 108 of the 137 recruited at baseline). All six sessions were attended by 52 out of the 108. Baseline scores for the 108 who completed post-course 
Table 3 Baseline and Postcourse scores (mean and standard deviation) $(n=108)$

\begin{tabular}{llll}
\hline Variable (score range, score meaning) & $\begin{array}{l}\text { Baseline } \\
\text { Mean (SD) }\end{array}$ & $\begin{array}{l}\text { Post-course } \\
\text { Mean (SD) }\end{array}$ & $\begin{array}{l}\text { Effect size of change } \\
\text { (Cohen's } d \text { ) }\end{array}$ \\
\hline Hope $(6-48, \uparrow=$ better) & $25.9(9.42)$ & $36.8(5.73)$ & $1.02^{*}$ \\
Gratitude $(6-42, \uparrow=$ better) & $28.6(7.01)$ & $34.5(4.46)$ & $0.90^{*}$ \\
$\begin{array}{l}\text { Positive mental well-being (14-70, } \\
\uparrow=\text { better) }\end{array}$ & $38.8(8.48)$ & $49.9(8.29)$ & $1.10^{*}$ \\
Depression $(0-21, \downarrow=$ better) & $9.0(4.36)$ & $5.4(3.45)$ & $0.81^{*}$ \\
Anxiety $(0-21, \downarrow=$ better) & $11.7(4.67)$ & $8.4(3.41)$ & $0.81^{*}$ \\
\hline
\end{tabular}

*Significant at $p<0.0001$ data were compared to the 29 with only baseline data, to explore any systematic patterns in drop-out.

No significant differences were found between those who dropped out and those who completed the intervention, in gender of parent, gender of the child, presence of parents medical problems, whether formal education completed or not, whether in paid employment or not, whether their child has any siblings, ethnicity of parents (collapsed to White/ European compared to other categories, owing to participant characteristics); nor marital status. All parents with a child without an ASD diagnosis completed post-course data, whereas $83 / 112(74 \%)$ of those with a child with an ASD diagnosis completed. This was significantly different $\left(\mathrm{X}^{2}(1)=8.211, p=0.004\right)$.

Anxiety $(\mathrm{U}=1579.5, \mathrm{Z}=0.071, p=0.943)$, depression, $(\mathrm{U}=1377.0, \mathrm{Z}=0.999, p=0.318)$, hope $(\mathrm{U}=1375.5$, $\mathrm{Z}=1.005, p=0.315)$, gratitude $(\mathrm{U}=1404.0, \mathrm{Z}=0.855$, $p=0.393)$, well-being $(\mathrm{U}=1557.0, \mathrm{Z}=0.047, p=0.962)$, age of parent $(\mathrm{U}=1303.0, \mathrm{Z}=0.853, p=0.397)$, and age of child ( $\mathrm{U}=1420.5, \mathrm{Z}=0.207, p=0.836$ ) were all not significantly different between those who did/did not complete the intervention. Only time since diagnosis was significantly different at $p<0.05(\mathrm{U}=956.5, \mathrm{Z}=2.205, p=$ 0.027): those who did not provide post-course data were more likely to have been diagnosed more recently.

Both presence of ASD diagnosis and time since diagnosis then require further investigation, as both were linked to non-completion of the intervention. Given that only parents with a child with an ASD diagnosis dropped out after baseline (26\% of these parents who enrolled at baseline did not complete), it is important to examine differences at baseline and post-course between those with and without the ASD diagnosis. Anxiety, depression, wellbeing, hope and gratitude at both time points were compared between those who had ASD diagnosis and those without. All comparisons were non-significant at $p<0.05$ (for brevity these are not reported in full, please contact authors for details). As such, it appears that for these data, presence of ASD diagnosis is unrelated to our intervention outcomes. Similarly, time since diagnosis did not significantly correlate with baseline anxiety, gratitude, hope, well-being or depression at $p<0.05$ using the necessary non-parametric tests as time since diagnosis is not normally distributed (exhibiting positive skew and leptokurtosis).

\section{Change in Outcome Measures between Baseline and Post-Course}

Paired sample t-tests were used to compare baseline and post-course scores for the 108 participants (who completed post course data collection and attended at least three of six sessions). There were significant differences for hope $(\mathrm{t}(107)=-10.635)$, gratitude $(\mathrm{t}(107)=-9.343)$, positive mental well-being $(\mathrm{t}(107)=-11.400)$, anxiety $(\mathrm{t}(107)=$ 8.393), and depression $(\mathrm{t}(107)=8.444)$, all achieving $p<$ 0.0001 . Table 3 provides means and effect sizes, which are all large (Cohen 1988).

\section{Change in Clinical "Caseness"}

Probable clinical "caseness" of depression (scoring above cut-off) was indicated for 39 of 108 participants at baseline. Of these, scores indicated potential "recovery" (drop below clinical cut-off score) from depression in 33 participants $(85 \%)$ at post-course. A small number of participants (2 of $48,4 \%$ ) scoring as not depressed at baseline went on to score within the depressed range at post-course. For anxiety, 60 participants scored above the threshold indicating probable clinical "caseness" of anxiety at baseline. Of these, scores indicated potential "recovery" from anxiety in 35 participants $(58 \%)$ at post-course. 7 of the $48(14.6 \%)$ scoring as not anxious at baseline moved to scoring within the anxious range by post-course.

\section{Relationship between Hope, Gratitude, Depression and Anxiety}

Correlations between anxiety, depression, well-being and hope and gratitude at baseline and post-course are displayed in Table 4. Baseline depression, anxiety and wellbeing correlated with baseline hope and gratitude, but not post-course hope or gratitude. Post-course outcomes variables correlated with post-course hope and gratitude. Post-course anxiety and depression did not correlate 
Table 4 Pearson's correlations between anxiety, depression, well-being, hope and gratitude $(N=108)$

\begin{tabular}{|c|c|c|c|c|c|c|c|c|c|}
\hline & 1 & 2 & 3 & 4 & 5 & 6 & 7 & 8 & 9 \\
\hline 1. Anxiety baseline & - & & & & & & & & \\
\hline 2. Depression baseline & $0.752^{* *}$ & - & & & & & & & \\
\hline 3. Well-being baseline & $-0.559^{* *}$ & $-0.665^{* *}$ & - & & & & & & \\
\hline 4. Anxiety post-course & $0.547^{* *}$ & $0.350^{* *}$ & $-0.293^{* *}$ & - & & & & & \\
\hline 5. Depression post-course & $0.311^{* *}$ & $0.377^{* *}$ & $-0.286^{* *}$ & $0.571^{* *}$ & - & & & & \\
\hline 6. Well-being post-course & -0.028 & -0.093 & $0.271^{* *}$ & $-0.337^{* *}$ & $-0.426^{* *}$ & - & & & \\
\hline 7. Hope baseline & $-0.561^{* *}$ & $-0.570^{* *}$ & $0.653^{* *}$ & -0.144 & -0.120 & 0.083 & - & & \\
\hline 8. Gratitude baseline & $-0.477^{* *}$ & $-0.594^{* *}$ & $0.621^{* *}$ & -0.120 & -0.137 & 0.038 & $0.736^{* *}$ & - & \\
\hline 9. Hope post-course & 0.046 & -0.010 & $0.206^{*}$ & $-0.251^{* *}$ & $-0.432^{* *}$ & $0.462^{* *}$ & 0.082 & 0.148 & - \\
\hline 10. Gratitude post-course & -0.126 & -0.111 & $0.220^{*}$ & $-0.373^{* *}$ & $-0.514^{* *}$ & $0.360^{* *}$ & $0.208^{*}$ & $0.430^{* *}$ & $0.426^{* *}$ \\
\hline
\end{tabular}

$* p<0.05, * * p<0.01$

Table 5 Results of stepwise multiple regression for post-course depression, anxiety and well-being

\begin{tabular}{|c|c|c|c|c|c|c|}
\hline \multirow[b]{2}{*}{ Variable } & \multicolumn{2}{|l|}{ Post-course depression } & \multicolumn{2}{|l|}{ Post-course anxiety } & \multicolumn{2}{|l|}{ Post-course well-being } \\
\hline & $\beta(95 \% \mathrm{CI})$ & $\mathrm{R}^{2}$ change & $\beta(95 \% \mathrm{CI})$ & $\mathrm{R}^{2}$ change & $\beta(95 \% \mathrm{CI})$ & $\mathrm{R}^{2}$ change \\
\hline $\begin{array}{l}\text { Baseline } \\
\text { depression }\end{array}$ & $0.750 * *(0.341-0.771)$ & 0.13 & -0.129 & - & -0.123 & - \\
\hline Baseline anxiety & 0.270 & - & $0.440 * *(0.122-0.391)$ & 0.17 & 0.017 & - \\
\hline Baseline hope & 0.099 & - & 0.069 & - & $0.468 * *(0.122-0.560)$ & 0.08 \\
\hline $\begin{array}{l}\text { Post-course } \\
\text { hope }\end{array}$ & $-0.248 *(-0.260--0.023)$ & 0.13 & 0.008 & - & $0.273 *(0.077-0.632)$ & 0.07 \\
\hline $\begin{array}{l}\text { Baseline } \\
\text { gratitude }\end{array}$ & $0.668 * *(0.180-0.484)$ & 0.10 & 0.167 & - & $-0.687 * *(-1.125--0.422)$ & 0.10 \\
\hline $\begin{array}{l}\text { Post-course } \\
\text { gratitude }\end{array}$ & $-0.416^{* *}(-0.535--0.163)$ & 0.14 & -0.206 & - & $0.503 *(0.536-1.369)$ & 0.17 \\
\hline $\begin{array}{l}\text { Reduced work } \\
\text { hours }\end{array}$ & 0.049 & - & $0.249 *(0.153-0.2783)$ & 0.08 & $-0.235^{*}(-6.774--0.435)$ & 0.09 \\
\hline Age of child & 0.041 & - & $-0.257 *(-0.393--0.021)$ & 0.15 & -0.110 & - \\
\hline Parents age & 0.183 & & -0.012 & & -0.034 & \\
\hline Parents sex & 0.176 & & -0.153 & & 0.080 & \\
\hline $\begin{array}{l}\text { Parent in paid } \\
\text { employment }\end{array}$ & 0.065 & & 0.054 & & 0.015 & \\
\hline Sex of child & 0.050 & & -0.027 & & -0.059 & \\
\hline $\begin{array}{l}\text { Child has } \\
\text { siblings }\end{array}$ & 0.053 & & -0.011 & & -0.006 & \\
\hline
\end{tabular}

significantly with baseline hope or gratitude. Post-course well-being also correlated significantly with baseline hope and gratitude.

Three stepwise multiple linear regressions were used to examine if parent characteristics (age, gender, in paid employment, if reduced work hours), child characteristics (age, gender, time since diagnosis, only child/has siblings), hope, and gratitude at each time point significantly explained the outcome of post-course depression, anxiety or well-being, including in the model baseline outcome scores. The detailed results are presented in Table 5.
For depression, when all variables were entered into the final model, baseline depression, post-course hope, baseline gratitude and post-course gratitude explained $50 \%$ of the variance in post-course depression scores $(\mathrm{F}(4,51)=$ $12.785, p<0.001)$. Based on condition indices, there is possible collinearity for post-course hope, baseline gratitude, and post-course gratitude (indices greater than 15 but less than 30). For anxiety, neither baseline nor post-course hope or gratitude associated with post-course anxiety. The significantly associated variables were baseline anxiety, age of the child, and if working hours had been reduced, 
Table 6 Results from the health education impact questionnaire $(n=108)$

\begin{tabular}{lll}
\hline Item & Mean score & (s.d.) \\
\hline 1. I intend to tell other people that the programme was very worthwhile & 3.7 & $(0.61)$ \\
2. The programme has helped me set goals that are reasonable and within reach & 3.4 & $(0.63)$ \\
3. I trust the information and advice I was given in the programme & 3.3 & $(0.62)$ \\
4. Course leaders were very well organized & 3.7 & $(0.56)$ \\
5. I feel it was worth my time and effort to take part in the programme & 3.8 & $(0.59)$ \\
6. Difficult topics and discussions were handled well by the programme leaders & 3.4 & $(0.63)$ \\
7. I thought that programme content was very relevant to my situation & 3.4 & $(0.67)$ \\
8. I feel that everyone in the programme had a chance to speak if they wanted & 3.5 & $(0.6)$ \\
9. The people in the group worked very well together & 3.7 & $(0.57)$ \\
\hline
\end{tabular}

together accounting for $40 \%$ of the variance in post-course anxiety $(\mathrm{F}(3,52)=11.448, p<0.001)$.

Post-course and baseline gratitude, post-course and baseline hope, and whether working hours had been reduced accounted for $51 \%$ of the variance in post-course well-being $(\mathrm{F}(5,50)=10.361, p<0.001)$. Condition indices suggest possible collinearity for baseline gratitude, baseline hope, and post-course hope (indices greater than 15 but less than 30).

\section{Perceived Impact of the Intervention}

HEIQ scores indicated that participants found the intervention relevant, trustworthy and were generally in agreement that the sessions were well organised and run. Table 6 provides mean scores, with a possible range of $1-4$.

\section{Discussion}

Parents who completed a 6-week face-to-face HOPE selfmanagement intervention were found to have significantly lower anxiety and depression scores, and higher positive mental well-being, gratitude and hope following the intervention. Furthermore, the change in depression and anxiety scores was from clinical levels to non-clinical levels, indicating potential "recovery" from anxiety for $58 \%$ of those anxious at baseline and from depression for $85 \%$ of those depressed at baseline. Relationships between anxiety, depression and well-being, as outcome variables, and gratitude and hope were largely as expected in the correlational analysis, with significant associations between variables at the same time point. Multiple regression analyses revealed post-course depression and well-being were explained to some extent by hope and gratitude, however, post-course anxiety was not.

Effect sizes for baseline to post-course changes were large. It must be kept in mind that these relate to pre-post comparisons rather than to differences between treatment and control groups. A randomised control trial is required to provide further insight into effect. Of participants enrolling on the course, $78.8 \%$ were retained, comparable to rates seen for psychological interventions with adults (Swift and Greenberg 2012). Although this study does not formally assess feasibility, the retention rates, data completion, scores on the HEIQ, and the fact that the intervention was delivered successfully by peer facilitators all support potential feasibility. Interestingly, of those who did not complete the study, all were parents of children with ASD, rather than another DD. This may indicate an issue with retention for these parents in the study, or may reflect another shared characteristic we did not measure, or may be due to other factors. Future studies should carefully examine retention of parents of children with ASD, and collate evidence of formal diagnosis to do this robustly.

We observed anxiety and depression scores reducing to probable non-clinical levels for $58 \%$ and $85 \%$, respectively of those with probable clinical levels at baseline. A coarse comparison with general population summary recovery rates for adults presenting for primary care mental health support are reported as around $46 \%$ for anxiety and $51-87 \%$ for depression (Hofmann et al. 2012), similar to our findings. Some participants moved into caseness at the end of the intervention, suggesting deterioration, which must be monitored further in future work.

Our six-week intervention was delivered by minimally trained peer facilitators, who received just two days of training. CBT therapists and those therapists used in other parent programs (e.g., Dykens et al. 2014) receive significantly more training than in this study, with its associated costs. Peer facilitators, here with lived experience of caring for children with DD, have been shown to be effective by acting as a positive role model of someone in a similar situation doing well, thus often increasing hope and confidence and being able to develop relationships with participants that appear to facilitate trust in intervention content (Turner and Martin 2017). Peer facilitated interventions represent part of the popular "task-shifting" model where more health-care work is completed by nonspecialists (Fulton et al. 2011). Adequate training and 
ongoing supervision are required and the research into the cost-effectiveness of this approach for parents of children with DD is needed.

In relation to our theoretical framework focusing on the role of hope and gratitude, we found these variables were associated to post-course scores for depression and wellbeing. Each variable individually explained up to a maximum of $17 \%$ of the variance in the outcome of depression or well-being, suggesting that although hope and gratitude may be potential mechanisms of change, they are not the only such mechanisms and there are other, unmeasured variables that are accounting for a large proportion of the change in outcomes. Nevertheless, there are theoretical implications for the potential mechanisms of change for interventions seeking to improve mental health outcomes for parents of children with DD. Previous research has documented links between mental health and gratitude and hope (Arnau et al. 2007; Chang and DeSimone 2001; Geiger 2013; Kwon 2000; Magaletta and Oliver 1999). Hope and gratitude are largely cognitive processes (Snyder 1995), which may create greater positive affect thereby directly addressing depression (Fredrickson et al. 2000) or may also change coping behaviours such as the use of social support (Griffith et al. 2012), thereby impacting depression. Further research should explore associations between changes in hope as mediated by changes in coping behaviours to better understand these potential pathways. The lack of significant association of post-course anxiety to gratitude and hope must be further explored: it may be due to small sample size or that anxiety is more related to other mechanisms of change than hope and gratitude. Conceptually although depression measures often include an indication of hope, for example, anxiety measures do not. It is conceivable to experience anxiety together with hope and gratitude. Further research is required to understand how our intervention may improve anxiety: it may be the normalising effect of being in a group that reduces anxiety (Waller et al. 2007).

The hope and gratitude activities within the HOPE Programme may be impacting depression. Of course, it may be a different pathway. One possibility is that the availability of social support in the HOPE course is what increases hope and gratitude, which in turn mediates the change in outcomes. Further research with inclusion of measures of coping and affect state would elucidate these potential pathways.

The focus of the HOPE Programme on strength building, rather than repairing deficits, sets it apart from classic clinical psychology focused interventions, which have their roots in a deficit model (Grant et al. 2010). Parents of children with DD including ASD report significant experience of stigma, often with a sense of isolation from "normal" families and a focus by others on their child's perceived deficits (Gray 2002). An intervention designed to explicitly address parental well-being, and to focus on strengths, to some extent goes against this stigma and creates a new social narrative. The use of peer facilitators may assist in tackling stigma and offering normalising experiences to parents, creating a sense of shared life experiences and offering vital emotional support (Dennis 2003). Further qualitative work should explore participants' and facilitators' views of their role and whether inclusion of formal experts in intervention delivery would be of perceived benefit.

\section{Limitations}

This study has no control group. A randomised controlled trial, with a control group receiving usual care, is the next step. Adverse effects were potentially observed: some participants reported worse anxiety and depression at postcourse. Inclusion of a control group would allow consideration of whether rates of this pattern of scores are also seen where no intervention/treatment as usual is offered. Additionally, an extended post-course period is required to explore how long any positive effects are maintained for.

We were unable to measure fidelity of the facilitators to the course manual and this should be included in a full trial. We used a commonly-used definition of three of six sessions as constituting completion of the course and further research should explore dose-response relationships and whether attendance at particular sessions is specifically related to greater/lesser change in outcomes.

We included parents of children with any DD, and it may be useful to explore effectiveness of the intervention between parents of children with different diagnoses. Furthermore, some of our participants' children had not yet received formal diagnosis, opening the possibility of a further source of variance. We did not seek formal confirmation of diagnoses, rather used parental report only. Whilst the vast majority of parents reported that their child had a clinician confirmed diagnosis, it would be preferable in a fully powered trial to ensure evidence and specific details of the diagnoses.

We noted that $100 \%$ of parents with children with diagnoses other than ASD completed the intervention, but only $74 \%$ of parents with children with an ASD diagnosis completed the intervention. It is not clear why, it may be that the material was less relevant to parents of children with ASD or that parents of children with ASD had greater access to other sources of support. Supplementing any future trial with qualitative studies to examine issues such as participant drop-out would help elucidate these issues. With a large sample size, it would be possible to also explore the impact of other variables such as group size and participants characteristics on outcomes. More detailed clinical 
assessment of parents' depression and anxiety would also strengthen the study methodology. Those who were retained in the intervention had been diagnosed longer than those who did not complete the intervention, therefore it is important to consider when this intervention could be offered to parents and what other approaches may be important closer to the time of diagnosis. Measures used in this study are self-report and may of course be subject to the effect of social desirability. This may be limited in the future by using non-face-to-face completion of measures.

The multiple regression analyses included a limited number of independent variables, owing to the sample size. A larger sample size for an RCT should allow inclusion of further independent variables or "predictors" including more detailed participant characteristics. There is possible collinearity observed in the regression analyses for postcourse depression and well-being, however, given the lack of very strong correlations observed, it is not clear the extent to which this is problematic. Further research with larger sample sizes should explore this in more detail. A qualitative investigation would be useful to further explore the reasons for participants dropping out of the course.

In conclusion, the HOPE programme delivered by minimally trained peer facilitators demonstrated change between baseline and post-course for parents' depression, anxiety and positive mental well-being, gratitude and hope. Gratitude and hope were associated with post-course depression and well-being. This is one of few studies examining interventions to specifically address well-being amongst parents of children with DD including ASD. Principles from positive psychology, giving rise to a simple and easy to deliver intervention, warrant further investigation as treatments to improve well-being for this group of parents.

Acknowledgements No funding was received for this study.

Author Contributions F.M.: analyzed data and wrote the paper. W.C.: assisted in study design and contributed to writing of the study. G.P.: collaborated with the design and writing of the study. A.T.: conceived of and designed the study, contributed to the writing and editing of the final manuscript.

\section{Compliance with Ethical Standards}

Conflict of Interest The authors declare that they have no conflict of interest.

Ethical Approval All procedures performed in studies involving human participants were in accordance with the ethical standards of the institutional research committee at Coventry University and with the 1964 Helsinki declaration and its later amendments or comparable ethical standards.

Informed Consent Informed consent was obtained from all individual participants included in the study.
Publisher's note: Springer Nature remains neutral with regard to jurisdictional claims in published maps and institutional affiliations.

Open Access This article is distributed under the terms of the Creative Commons Attribution 4.0 International License (http://crea tivecommons.org/licenses/by/4.0/), which permits use, duplication, adaptation, distribution, and reproduction in any medium or format, as long as you give appropriate credit to the original author(s) and the source, provide a link to the Creative Commons license, and indicate if changes were made.

\section{References}

Arnau, R. C., Rosen, D. H., Finch, J. F., Rhudy, J. L., \& Fortunato, V. J. (2007). Longitudinal effects of hope on depression and anxiety: A latent variable analysis. Journal of Personality, 75(1), 43-64.

Barlow, J., Wright, C., Sheasby, J., Turner, A., \& Hainsworth, J. (2002). Self-management approaches for people with chronic conditions: a review. Patient Education \& Counseling, 48, 177-187.

Bibby, P., Eikeseth, S., Martin, N. T., Mudford, O. C., \& Reeves, D. (2002). Progress and outcomes for children with autism receiving parent-managed intensive interventions. Research in Developmental Disabilities, 23(1), 81-104.

Bjelland, I., Dahl, A. A., Haug, T. T., \& Neckelmann, D. (2002). The validity of the Hospital Anxiety and Depression Scale. An updated literature review. Journal of Psychosomatic Research, 52 (2), 69-77.

Bolier, L., Haverman, M., Westerhof, G. J., Riper, H., Smit, F., \& Bohlmeijer, E. (2013). Positive psychology interventions: a metaanalysis of randomized controlled studies. BMC Public Health, 13(1), 119-138.

Brooks, H. L., Rogers, A., Sanders, C., \& Pilgrim, D. (2015). Perceptions of recovery and prognosis from long-term conditions: The relevance of hope and imagined futures. Chronic Illness, 11 (1), 3-20.

Chang, E. C., \& DeSimone, S. L. (2001). The influence of hope on appraisals, coping, and dysphoria: A test of hope theory. Journal of Social and Clinical Psychology, 20(2), 117-129.

Cheavens, J. S., Feldman, D. B., Gum, A., Michael, S. T., \& Snyder, C. (2006). Hope therapy in a community sample: A pilot investigation. Social Indicators Research, 77(1), 61-78.

Clifford, T., \& Minnes, P. (2013). Who participates in support groups for parents of children with autism spectrum disorders? The role of beliefs and coping style. Journal of Autism and Developmental Disorders, 43(1), 179-187.

Cohen, J. (1988). Statistical Power Analysis for the Behavioral Sciences. 2nd edn. New Jersey: Lawrence Erlbaum Associates, Inc.

Craig, P., Dieppe, P., Macintyre, S., Michie, S., Nazareth, I., \& Petticrew, M. (2008). Developing and evaluating complex interventions the new medical research council guidance. British Medical Journal, 337, a1655.

Crawford, J., Henry, J., Crombie, C., \& Taylor, E. (2001). Normative data for the HADS from a large non-clinical sample. British Journal of Clinical Psychology, 40(4), 429-434.

Cyhlarova, E., Crepaz-Keay, D., Reeves, R., Morgan, K., Iemmi, V., \& Knapp, M. (2015). An evaluation of peer-led self-management training for people with severe psychiatric diagnoses. The Journal of Mental Health Training, Education and Practice, 10(1), 3-13.

Da Paz, N. S., \& Wallander, J. L. (2017). Interventions that target improvements in mental health for parents of children with autism spectrum disorders: a narrative review. Clinical Psychology Review, 51, 1-14. 
Dababnah, S., \& Parish, S. L. (2015). Feasibility of an empirically based program for parents of preschoolers with autism spectrum disorder. Autism, 20(1), 85-95.

Dababnah, S., \& Parish, S. L. (2016). A comprehensive literature review of randomized controlled trials for parents of young children with autism spectrum disorder. Journal of Evidenceinformed Social Work, 13(3), 277-292.

Dennis, C.-L. (2003). Peer support within a health care context: a concept analysis. International Journal of Nursing Studies, 40(3), 321-332.

Dykens, E. M., Fisher, M. H., Taylor, J. L., Lambert, W., \& Miodrag, N. (2014). Reducing distress in mothers of children with autism and other disabilities: a randomized trial. Pediatrics, 134(2), E454-E463.

Ekas, N. V., Pruitt, M. M., \& McKay, E. (2016). Hope, social relations, and depressive symptoms in mothers of children with autism spectrum disorder. Research in Autism Spectrum Disorders, 29-30, 8-18.

Emmons, R. A., \& McCullough, M. E. (2003). Counting blessings versus burdens: an experimental investigation of gratitude and subjective well-being in daily life. Journal of Personality and Social Psychology, 84, 377-389.

Falk, N. H., Norris, K., \& Quinn, M. G. (2014). The factors predicting stress, anxiety and depression in the parents of children with autism. Journal of Autism and Developmental Disorders, 44(12), 3185-3203.

Fredrickson, B. L., Mancuso, R. A., Branigan, C., \& Tugade, M. M. (2000). The undoing effect of positive emotions. Motivation and Emotion, 24(4), 237-258.

Fulton, B. D., Scheffler, R. M., Sparkes, S. P., Auh, E. Y., Vujicic, M., \& Soucat, A. (2011). Health workforce skill mix and task shifting in low income countries: a review of recent evidence. Human Resources for Health, 9(1), 1 https://doi.org/10.1186/1478-44919-1.

Geiger, K. A. (2013). Understanding hope and self-efficacy in predicting symptoms of depression. Pullman, Washington, USA: Washington State University.

Gordon, C. T., \& Hinshaw, S. P. (2015). Parenting stress as a mediator between childhood ADHD and early adult female outcomes. Journal of Clinical Child \& Adolescent Psychology, 46(4), 588-599.

Grant, A., Townend, M., Mulhern, R., \& Short, N. (2010). Cognitive Behavioural Therapy in Mental Health Care. London: Sage.

Gray, D. E. (2002). 'Everybody just freezes. Everybody is just embarrassed': felt and enacted stigma among parents of children with high functioning autism. Sociology of Health \& Illness, 24 (6), 734-749.

Griffith, G. M., Totsika, V., Nash, S., Jones, R. S. P., \& Hastings, R. P. (2012). "We are all there silently coping." The hidden experiences of parents of adults with Asperger syndrome. Journal of Intellectual \& developmental disability, 37(3), 237-247.

Griffiths, C., Motlib, J., Azad, A., Ramsay, J., Eldridge, S., Feder, G., Khanam, R., Munni, R., Garrett, M., Turner, A., \& Barlow, J. (2005). Randomised controlled trial of a lay-led self-management programme for Bangaldeshi patients with chronic disease. British Journal of General Practice, 55, 831-837.

Gupta, V. B. (2007). Comparison of parenting stress in different developmental disabilities. Journal of developmental and Physical disabilities, 19(4), 417-425.

Hair, J., Black, W., Babin, B., \& Anderson, R. (2010). Advanced diagnostics for multiple regression: A supplement to multivariate data analysis. Upper Saddle River, NJ: Prentice Hall.

Hall, H. R., \& Graff, J. C. (2012). Maladaptive behaviors of children with autism: parent support, stress, and coping. Issues in Comprehensive Pediatric Nursing, 35(3-4), 194-214.
Hassall, R., \& Rose, J. (2005). Parental cognitions and adaptation to the demands of caring for a child with an intellectual disability: a review of the literature and implications for clinical interventions. Behavioural and Cognitive Psychotherapy, 33(01), 71-88.

Hayes, S. A., \& Watson, S. L. (2013). The impact of parenting stress: a meta-analysis of studies comparing the experience of parenting stress in parents of children with and without autism spectrum disorder. Journal of Autism and Developmental Disorders, 43(3), 629-642.

Heiman, T., \& Berger, O. (2008). Parents of children with Asperger syndrome or with learning disabilities: family environment and social support. Research in Developmental Disabilities, 29(4), 289-300.

Herring, S., Gray, K., Taffe, J., Tonge, B., Sweeney, D., \& Einfeld, S. (2006). Behaviour and emotional problems in toddlers with pervasive developmental disorders and developmental delay: associations with parental mental health and family functioning. Journal of Intellectual Disability Research, 50(12), 874-882.

Hofmann, S. G., Asnaani, A., Vonk, I. J. J., Sawyer, A. T., \& Fang, A. (2012). The efficacy of cognitive behavioral therapy: a review of meta-analyses. Cognitive Therapy and Research, 36(5), 427-440.

Johnston, C., \& Mash, E. J. (2001). Families of children with attention-deficit/hyperactivity disorder: review and recommendations for future research. Clinical Child and Family Psychology Review, 4(3), 183-207.

Joshi, P. T., McHattie, D., Malin, C., Dingley, W., Edwards, R., \& Turner, A. (2013). Meet the parents: Can group based selfmanagement improve psychological well-being and reduce psychological distress for parent caregivers of chilcdren with ASD and /or ADHD? Paper presented at the Division of Health Psychology Conference, Brighton, UK.

Karst, J. S., \& Van Hecke, A. V. (2012). Parent and family impact of autism spectrum disorders: a review and proposed model for intervention evaluation. Clinical Child and Family Psychology Review, 15(3), 247-277.

Kazdin, A. E. (2007). Mediators and mechanisms of change in psychotherapy research. Annual Review of Clinical Psychology, 3, $1-27$.

Kerr, S. L., O’Donovan, A., \& Pepping, C. A. (2015). Can gratitude and kindness interventions enhance well-being in a clinical sample? Journal of Happiness Studies, 16(1), 17-36.

Kinnear, S. H., Link, B. G., Ballan, M. S., \& Fischbach, R. L. (2016). Understanding the experience of stigma for parents of children with autism spectrum disorder and the role stigma plays in families' lives. Journal of Autism and Developmental Disorders, 46(3), 942-953.

Krakovich, T. M., McGrew, J. H., Yu, Y., \& Ruble, L. A. (2016). Stress in Parents of children with autism spectrum disorder: an exploration of demands and resources. Journal of Autism and Developmental Disorders, 46(6), 2042-2053.

Kwon, P. (2000). Hope and dysphoria: the moderating role of defense mechanisms. Journal of Personality, 68(2), 199-223.

Lambert, N. M., Clark, M. S., Durtschi, J., Fincham, F. D., \& Graham, S. M. (2010). Benefits of expressing gratitude expressing gratitude to a partner changes one's view of the relationship. Psychological Science, 21(4), 574-580.

Larsen, D. J., King, R. L., Stege, R., \& Egeli, N. A. (2015). Hope in a strengths-based group activity for individuals with chronic pain. Counselling Psychology Quarterly, 28(2), 175-199.

Lopez, S. J., Ciarlelli, R., Coffman, L., Stone, M., \& Wyatt, L. (2000). Diagnosing for strengths: on measuring hope building blocks. In C. Snyder (Ed.), Handbook of Hope (pp. 57-85). London, UK: Academic Press.

Magaletta, P. R., \& Oliver, J. (1999). The hope construct, will, and ways: their relations with self-efficacy, optimism, and general well-being. Journal of Clinical Psychology, 55(5), 539-551. 
McCullough, M. E., Emmons, R. A., \& Tsang, J. (2002). The grateful disposition: a conceptual and empirical topography. Journal of Personality and Social Psychology, 82, 112-127.

Miranda, A., Tárraga, R., Fernández, M. I., Colomer, C., \& Pastor, G. (2015). Parenting stress in families of children with autism spectrum disorder and ADHD. Exceptional Children, 82(1), $81-95$.

Osborne, R. H., Elsworth, G. R., \& Whitfield, K. (2007). The health education impact questionnaire (heiQ): an outcomes and evaluation measure for patient education and self-management interventions for people with chronic conditions. Patient Education and Counseling, 66(2), 192-201.

Padden, C., \& James, J. E. (2017). Stress among parents of children with and without autism spectrum disorder: a comparison involving physiological indicators and parent self-reports. Journal of developmental and Physical disabilities, 29(4), 567-586.

Petrocchi, N., \& Couyoumdjian, A. (2016). The impact of gratitude on depression and anxiety: the mediating role of criticizing, attacking, and reassuring the self. Self and Identity, 15(2), 191-205.

Schrank, B., Stanghellini, G., \& Slade, M. (2008). Hope in psychiatry: a review of the literature. Acta Psychiatrica Scandinavica, 118 (6), 421-433.

Snyder, C. R. (1995). Conceptualizing, measuring, and nurturing hope. Journal of Counseling and Development, 73(3), 355.

Snyder, C. R., Harris, C., Anderson, J. R., Holleran, S. A., Irving, L. M., \& Sigmon, S. T., et al. (1991). The will and the ways: Development and validation of an individual differences measure of hope. Journal of Personality and Social Psychology, 60, $570-585$

Snyder, C. R., Rand, K. L., \& Sigmon, D. R. (2002). Hope theory: a member of the positive psychology family. In C. R. Snyder \& S. J. Lopez (Eds.), Handbook of Positive Psychology (pp. 257-276). New York: Oxford University Press.

Snyder, C. R., Sympson, S. C., Ybasco, F. C., Borders, T. F., Babyak, M. A., \& Higgins, R. L. (1996). Development and validation of the State Hope Scale. Journal of Personality and Social Psychology, 2, 321-335.

Swift, J. K., \& Greenberg, R. P. (2012). Premature discontinuation in adult psychotherapy: a meta-analysis. Journal of Consulting and Clinical Psychology, 80(4), 547-559.
Tennant, R., Hiller, L., Fishwick, R., Platt, S., Joseph, S., Weich, S., Parkinson, J., Secker, J., \& Stewart-Brown, S. (2007). The Warwick-Edinburg Mental Well-being Scale (WEMWBS): development and UK validation. Health and Quality of Life Outcomes, 5, 63-75.

Timmons, L., Ekas, N. V., \& Johnson, P. (2017). Thankful thinking: a thematic analysis of gratitude letters by mothers of children with autism spectrum disorder. Research in Autism Spectrum Disorders, 34, 19-27.

Timmons, L. N. (2015). The Effectiveness of a Gratitude Intervention at Improving Well-being for Parents of Children with Autism Spectrum Disorder. Texas Christian University.

Tugade, M. M., Fredrickson, B. L., \& Feldman Barrett, L. (2004). Psychological resilience and positive emotional granularity: Examining the benefits of positive emotions on coping and health. Journal of Personality, 72(6), 1161-1190.

Turner, A., \& Martin, F. (2017). Spreading HOPE: The Development of a Hope-Based Self-Management Intervention. In E. Martz (Ed.) Promoting Self-Management of Chronic Health Conditions: Theories and Practice. (pp. 58-79). Oxford: Oxford University Press.

Twoy, R., Connolly, P. M., \& Novak, J. M. (2007). Coping strategies used by parents of children with autism. Journal of the American Academy of Nurse Practitioners, 19(5), 251-260.

Veres, A., Bain, L., Tin, D., Thorne, C., \& Ginsburg, L. (2014). The neglected importance of hope in self-management programs-a call for action. Chronic Illness, 10(2), 77-80.

Waller, J., Marlow, L. A. V., \& Wardle, J. (2007). The association between knowledge of HPV and feelings of stigma, shame and anxiety. Sexually Transmitted Infections, 83(2), 155-159.

Weiss, M. J. (2002). Hardiness and social support as predictors of stress in mothers of typical children, children with autism, and children with mental retardation. Autism, 6(1), 115-130.

Wood, A. M., Froh, J. J., \& Geraghty, A. W. A. (2010). Gratitude and well-being: A review and theoretical integration. Clinical Psychology Review, 30(7), 890-905.

Zigmond, A., \& Snaith, R. (1983). The Hospital Anxiety And Depression Scale. Acta Psychiatrica Scandinavica, 67, 361-370. 